\title{
Helen Salisbury: Dis-integration of cancer care
}

\author{
Helen Salisbury GP \\ Oxford
}

We are lucky enough in our city to have a world class cancer treatment centre. But word is out that the contract for doing combined positron emission tomography and computed tomography scans for the region has been taken away from the local NHS trust and awarded to InHealth, a commercial provider of medical imaging. The contract, along with those for PET-CT imaging at other hospitals across the country, was put out to tender in 2016 by NHS England, and the local hospital's bid was not chosen. ${ }^{1}$

There are several reasons why this is a really bad idea. The scans are used in diagnosis, to find out whether cancer has spread, and to determine whether treatment has been effective. Currently radiologists are part of a multidisciplinary team who discuss and plan treatment for patients. If the NHS does not provide the service, how will we train the next generation of specialist cancer radiologists? In future, scans will be performed at a different site and will be reported by a radiologist who is not part of the team. And patients, some of them quite unwell, will need to travel off site to be scanned. Oxford's role as a major centre for PET-CT research is also at risk.

InHealth will need to build new premises for the scanners. It would be good to know how this move can be saving money, unless there is a reduction in the quality of the service, which is precisely what local doctors fear will happen. In the words of one local surgeon, "Let us be absolutely clear-if this goes ahead it will lead to patient harm."
The rationale for the decision offered by NHS England is that they were forced by EU procurement law to put this contract out to tender. ("Let's blame it on the EU"-sound familiar, anyone?) This is unconvincing, but it is revealing. So many parts of our NHS have been outsourced to profit driven corporations, and bids seem to have been judged disproportionately on how much money they will save rather than on the quality of the service that will be provided for patients.

The treatment of people with cancer is an emotive issue and, though this is only one in a long sequence of services previously delivered in the NHS that are now outsourced to private companies, local MPs and health bosses are up in arms. People are angry that the decision has been taken without consulting the local community or the council health board. When two major themes of the NHS long term plan are improving cancer care and greater integration, ${ }^{2}$ this move looks particularly ill timed.

Competing interests: See www.bmj.com/about-bmj/freelance-contributors. Provenance and peer review: Commissioned; not externally peer reviewed.

Campbell D. NHS cancer centre loses scanning contract to private firm. Guardian Mar 2019. https://www.theguardian.com/society/2019/mar/06/nhs-cancer-centre-loses-scanningcontract-to-private-firm.

2 NHS England. NHS long term plan. https://www.england.nhs.uk/long-term-plan.

Published by the BMJ Publishing Group Limited. For permission to use (where not already granted under a licence) please go to http://group.bmj.com/group/rights-licensing/ permissions 